\title{
Multifunctionalized CMCht/PAMAM Dendrimer Nanoparticles Modulate the Cellular Uptake by Astrocytes and Oligodendrocytes in Primary Cultures of Glial Cells
}

Susana R. Cerqueira, Bárbara L. Silva, Joaquim M. Oliveira, João F. Mano,

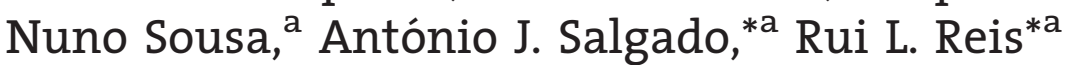

The efficiency of the treatments involving CNS disorders is commonly diminished by the toxicity, reduced stability and lack of targeting of the administered neuroactive compounds. In this study, we have successfully multifunctionalized CMCht/PAMAM dendrimer nanoparticles by coupling the $\mathrm{CD} 11 \mathrm{~b}$ antibody and loading MP into the nanoparticles. The modification of the new antibody-conjugated nanoparticles was confirmed by S-TEM observation and ${ }^{1} \mathrm{H}$ NMR and FTIR spectroscopy. Cytotoxicity assays revealed that the conjugates did not affect the viability of both primary cultures of glial and microglial cells. Trace analyses of FITClabelled nanoparticles revealed that the uptake of antibody-conjugated nanoparticles was conserved in microglial cells but significantly decreased in astrocytes and oligodendrocytes. Thus, this study demonstrates that antibody conjugation contributes to a modulation of the internalization of these nanocarriers by different cell types, which might be of relevance for specific targeting of CNS cell populations.

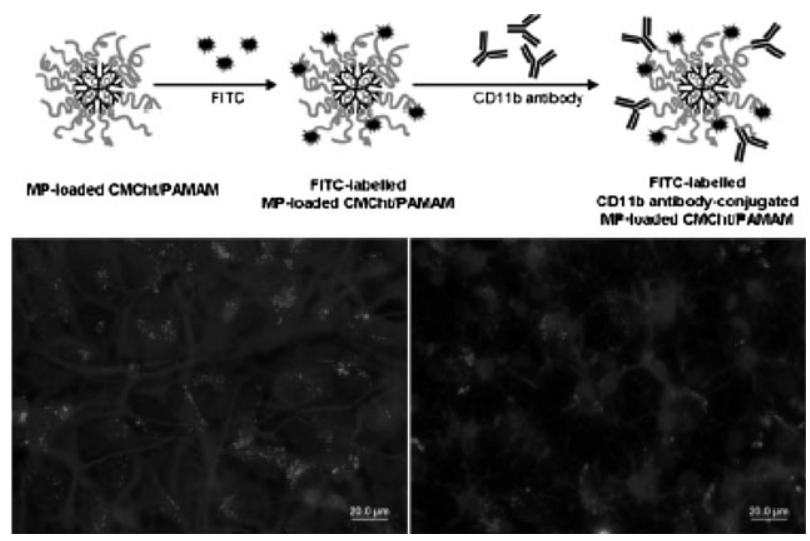

A. J. Salgado, R. L. Reis, S. R. Cerqueira, B. L. Silva, J. M. Oliveira, J. F. Mano, N. Sousa

ICVS/3B's - PT Government Associate Laboratory, Braga/ Guimarães, Portugal

Fax: (+351) 253510 909;

E-mail: asalgado@ecsaude.uminho.pt,rgreis@dep.uminho.pt

R. L. Reis, S. R. Cerqueira, J. M. Oliveira, J. F. Mano

3B's Research Group - Biomaterials, Biodegradables and

Biomimetics, University of Minho, Headquarters of the European Institute of Excellence on Tissue Engineering and Regenerative Medicine, AvePark, Zona Industrial da Gandra, S. Cláudio do Barco, 4806-909 Caldas das Taipas, Guimarães, Portugal
A. J. Salgado, S. R. Cerqueira, B. L. Silva, N. Sousa Life and Health Sciences Research Institute (ICVS), School of Health Sciences, University of Minho, 4710-057 Braga, Portugal

\footnotetext{
${ }^{a}$ These authors share senior authorship.
} 


\section{Introduction}

Drug delivery to the central nervous system (CNS) has been a considerable challenge in biomedical research in the past decades. ${ }^{[1,2]}$ Neurological disorders such as Alzheimer's and Parkinson's diseases, stroke, multiple sclerosis and also neurotraumatic conditions, such as spinal cord injury (SCI), are amongst the main debilitating disorders of our times. ${ }^{[3]}$ The unique environment and the complexity of the mechanisms involved in these conditions, some of which still poorly understood, have hindered the development of new and efficient treatments. The systemic administration of neuroactive molecules poses several intrinsic issues, particularly its toxicity and reduced stability in the organism. ${ }^{[4]}$ Thus, there is an urgent demand not only for more detailed knowledge of the pathophysiology of CNS disorders, but also for more specific and effective drug delivery strategies ${ }^{[5,6]}$ Another major issue for drug delivery in the CNS is the presence of biological barriers such as the blood-brain barrier (BBB) and the blood-cerebrospinal fluid barrier (BCSFB) that can obstruct the entry of therapeutic molecules to the nervous tissues. ${ }^{[7,8]}$ Nonetheless, one must distinguish diseases that do not affect the BBB integrity from those which compromise it. ${ }^{[9]}$ In the first case, the major obstacle to an effective cure of the disease is the BBB presence itself and its characteristics. However, when this barrier has been compromised, for instance, after neurotraumatic events, the delivery of compounds is clearly eased. ${ }^{[10]}$ In brain and SCI physical damage occurs and the CNS barriers are disrupted opening a 'window of opportunity' for the entry of drugs that can limit the extent of following potential secondary damage. ${ }^{[10,11]}$ Still, efficient drug delivery to the target cells remains a crucial task for the success of these therapies, since most of these drugs are often highly unspecific. $^{[12]}$

The use of nanoparticle-based systems has gained increasing interest in drug delivery with exciting prospects. ${ }^{[13]}$ These nanoscale materials present unique and advantageous features in comparison to the classical drug formulations, regarding its solubility, biodistribution, release characteristics and immunogenicity. ${ }^{[14]}$ In addition, nanoparticles are amenable to further modifications that can provide higher functionalization degrees, namely cell or tissue targeting. ${ }^{[13]}$ Fundamentally, nanoparticlemediated selective drug delivery would offer a mean to minimize delivery to unintended sites, allowing higher doses of drug to be administered when reaching a precise target site, thereby lowering peripheral cytoxicity. A critical step in such a strategy is the internalization of nanoparticles into specific cells, and a way to overcome it would be the modification of the nanoparticle surface with a ligand, that would be efficiently taken up by target cells. ${ }^{[15,16]} \mathrm{A}$ vast range of nanoparticles is being developed and investigated for specific drug delivery purposes although from these only a small percentage is being directed to CNS. ${ }^{[17,18]}$

A new surface engineered macromolecular carrier was recently proposed to be used in CNS applications, showing high internalization levels and no significant cytotoxicity over neurons and glial cells. ${ }^{[19]}$ Moreover, it has also shown to be non-cytotoxic in vivo, revealing a wide biodistribution after intravenous injections, being simultaneously able to cross the BCSFB. ${ }^{[20]}$ This system was firstly described as a new surface engineered nanoparticle based on a polyamidoamine (PAMAM) dendrimer core grafted with the natural polymer carboxymethylchitosan (CMCht). ${ }^{[21]}$ The sphere-like CMCht/PAMAM dendrimer nanoparticles were proposed to be used as targeted drug delivery carriers for the modulation of the cells' behaviour by efficient intracellular uptake upon its functionalization via: (i) drug incorporation; (ii) fluorescent labelling and (iii) ligand conjugation. ${ }^{[22]}$ Furthermore, an anti-inflammatory corticosteroid clinically used in SCI related cases-methylprednisolone (MP) - has already shown to be efficiently incorporated and released from these nanoparticles, leading to important alterations on the viability of primary cultures of microglial cells. ${ }^{[23]}$

Therefore, following recent developments of these previous works the aim of this study was to achieve a higher functionalization level of the CMCht/PAMAM dendrimer nanoparticles by conjugating to the latter a targeting ligand, in order to determine a possible modulation of their internalization behaviour in glial cells. From the variety of potential ligands to nanoparticles surfaces, monoclonal antibodies are attractive molecules due its high specificity. ${ }^{[24]}$ Therefore, the MP-loaded CMCht/PAMAM dendrimer nanoparticles were conjugated to the $\mathrm{CD} 11 \mathrm{~b}$ antibody which recognizes specific receptors on microglial cells' membranes. The multifunctional modification of the CMCht/PAMAM dendrimer nanoparticles was confirmed by Fourier transform infrared (FTIR) spectroscopy and proton nuclear magnetic resonance ( $\left.{ }^{1} \mathrm{H} N M R\right)$. Then, we have investigated its effects in the normal viability of glial and microglial cells, in vitro. Finally, an assessment and comparison of the two types of nanoparticles uptake in mixed glial cultures was done following immunocytochemistry and fluorescence microscopy observation. Results revealed that conjugated nanoparticles were not deleterious to both glial and microglial cells. Moreover, the internalization profile of the new nanoparticles in a mixed glial culture was indeed altered when compared to the unmodified nanoparticles. This study demonstrates that by following the above referred strategy it is possible to modulate the internalization of MP-loaded CMCht/PAMAM dendrimer nanoparticles by different glial cell populations, rendering them with a cell targeted profile for future CNS applications. 


\section{Experimental Section}

\subsection{Dendrimer Nanoparticles Preparation}

\subsubsection{Carboxymethylchitosan (CMCht)/ Polyamidoamine (PAMAM) Dendrimer Nanoparticles Synthesis}

Carboxymethylchitosan (CMCht)/PAMAM dendrimer nanoparticles were produced as previously reported by Oliveira et al. ${ }^{[21]}$ Starburst PAMAM-carboxylic acid terminated dendrimer solution (PAMAM-CT) (generation 1.5, 20\% w/v) was purchased (Sigma, Germany). The following reactions were carried out: (i) increase in the PAMAM-CT generation; (ii) production of a PAMAM-methyl ester terminated dendrimer; (iii) condensation reaction between the methyl ester and amine groups of PAMAM and CMCht and (iv) conversion of the non-reacting methyl ester groups into carboxylic ones in the CMCht/PAMAM dendrimer nanoparticles. Initially, the methanol was removed from the PAMAM-CT dendrimers by evaporation under nitrogen gas. The remaining compound was re-dissolved in ultra-pure water in a final concentration of $10 \mathrm{mg} \cdot \mathrm{mL}^{-1}$ and the $\mathrm{pH}$ was corrected to 6.5 . Then, 1-ethyl-3-(3-dimethylaminopropyl) carbodiimide hydrochloride (EDC, Fluka, Slovakia) was added under agitation for $30 \mathrm{~min}$ at room temperature. Ethylenediamine (EDA, Sigma, Germany) was included at the same molar ratio and reacted for $4 \mathrm{~h}$. The solution was subsequently dialysed against ultrapure water in order to remove the exceeding EDC (cellulose tubing, benzoylated for separating compounds with a molecular weight of $\leq 1$ 200, Sigma, Germany). The obtained amine terminated PAMAM dendrimers (PAMAM-AT) were mixed with methanol (Sigma, Germany) and methyl methacrylate (Fluka, Germany) and kept under agitation in a water bath at $50{ }^{\circ} \mathrm{C}$ for $24 \mathrm{~h}$. After methanol removal under nitrogen gas, appropriate volumes of hydrochloric acid (HCl, Panreac, Portugal) and trifluoroacetic acid (TFA, Sigma, Germany) were added to the solution. Meanwhile, 1 g of CMCht was dissolved in $50 \mathrm{~mL}$ of water. The PAMAM methyl ester terminated dendrimers were dissolved in a 20:80 water/methanol solution and the CMCht was added and kept under agitation for $72 \mathrm{~h}$, after which the CMCht/PAMAM dendrimer nanoparticles with carboxylicterminated groups were obtained.

\subsubsection{Methylprednisolone Incorporation into the CMCht/PAMAM Dendrimer Nanoparticles}

Methylprednisolone (MP) was incorporated in the nanoparticles by mixing an aqueous solution of CMCht/PAMAM dendrimer nanoparticles with an ethanolic MP solution with a final concentration of $5 \times 10^{-4} \mathrm{MW} / \mathrm{w}$ and kept under vigorous agitation. Saturated sodium carbonate solution $\left(\mathrm{Na}_{2} \mathrm{CO}_{3}\right.$, Aldrich, Germany) and acetone (Pronalab, Portugal) were then added to the mixture. The resulting precipitates were collected by filtration and then dispersed in ultrapure water. Extensive dialysis (cellulose tubing, benzoylated for separating compounds with a molecular weight of $\leq 1$ 200, Sigma, Germany) was performed during $48 \mathrm{~h}$. Both CMCht/PAMAM dendrimer nanoparticles and MP-loaded CMCht/ PAMAM dendrimer nanoparticles were obtained by freezing the final solution at $-80^{\circ} \mathrm{C}$ and freeze-drying (Telstar-Cryodos-80, Spain) the samples for approximately $7 \mathrm{~d}$, until the solvents were completely removed.

\subsubsection{Fluorescent Labelling of MP-loaded CMCht/PAMAM Dendrimer Nanoparticles}

Fluorescein isothiocyanate (FITC, Sigma, Germany) labelled MPloaded CMCht/PAMAM dendrimer nanoparticles conjugates were prepared by covalently bonding the amine group of CMCht and the isothiocyanate group from FITC (Scheme 1). A $10 \mathrm{mg} \cdot \mathrm{mL}^{-1}$ FITC solution was prepared in dimethyl sulphoxide anhydrous (DMSO, Riedel-de Haen, Germany) in the dark. Simultaneously, a $10 \mathrm{mg} \cdot \mathrm{mL}^{-1}$ MP-loaded CMCht/PAMAM dendrimer nanoparticles solution was set in carbonate-bicarbonate coupling buffer $(\mathrm{pH}=9.2)$. Afterwards, $50 \mu \mathrm{L}$ of the FITC/DMSO solution were added per each $\mathrm{mL}$ of the MP-loaded CMCht/PAMAM dendrimer nanoparticles buffered solution, under agitation. The resulting solution was kept in the dark at $4{ }^{\circ} \mathrm{C}$ for $8 \mathrm{~h}$. The FITC-labelled MPloaded CMCht/PAMAM dendrimer nanoparticles solution was then dialysed (cellulose tubing, benzoylated for separating compounds with a molecular weight of $\leq 1200$, Sigma, Germany) for $48 \mathrm{~h}$ against ultrapure water in order to remove the FITC molecules that did not react. Finally, the solution was frozen at $80^{\circ} \mathrm{C}$ and subsequently freeze-dried (Telstar-Cryodos-80, Spain) until the solvents were completely removed.

\subsubsection{CD11b Antibody Conjugation to CMCht/PAMAM Dendrimer Nanoparticles}

In order to conjugate anti-mouse $\mathrm{CD} 11 \mathrm{~b}$ antibody (BD Biosciences, USA) to the dendrimer nanoparticles a crosslinking reaction was performed (Scheme 1). ${ }^{[25]} \mathrm{A} 20 \mathrm{mg} \cdot \mathrm{mL}^{-1}$ solution of nanoparticles in phosphate buffer saline (PBS) was mixed with $1 \mathrm{mg} \cdot \mathrm{mL}^{-1} \mathrm{EDC}$ (Fluka, Slovakia) and let react for $30 \mathrm{~min}$. The remaining solution was dialysed against ultrapure water for $24 \mathrm{~h}$ to remove the excess EDC. Afterwards, the $\mathrm{pH}$ was corrected to 7.4 and $4 \mathrm{nmol}$ of $\mathrm{CD} 11 \mathrm{~b}$ antibody were added under agitation. One hour after CD11b addition, the solution was frozen at $-80^{\circ} \mathrm{C}$ and subsequently freeze-dried (Telstar-Cryodos-80, Spain).

\subsubsection{Characterization of the CD11b Antibody Conjugated Dendrimer Nanoparticles}

The conjugation effectiveness was analysed by FTIR spectroscopy and ${ }^{1} \mathrm{H}$ NMR. The morphology of the new conjugated nanoparticles was assessed by scanning-transmission electron micro-

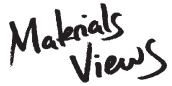

www.MaterialsViews.com
Macromol. Biosci. 2012, 12, 591-597

(C) 2012 WILEY-VCH Verlag GmbH \& Co. KGaA, Weinheim 
scopy (S-TEM). To obtain the FTIR spectra of the samples, transparent potassium bromide ( $\mathrm{KBr}$, Pike Technologies, USA) pellets were prepared containing the samples to be analysed. The readings were run in an infrared spectroscope (IR Prestige-21, Shimadzu, Japan). For the ${ }^{1} \mathrm{H}$ NMR analyses the samples were dispersed in deuterium oxide $\left(\mathrm{D}_{2} \mathrm{O}\right.$, Aldrich, Germany) at a final concentration of $10 \mathrm{mg} \cdot \mathrm{mL}^{-1}$. The one-dimensional ${ }^{1} \mathrm{H}$ spectra were acquired in a Varian Unity Plus spectrometer at $300 \mathrm{MHz}$ and $20^{\circ} \mathrm{C}$. The morphology was then verified by S-TEM (Nova NanoSEM 50 series, FEI Company, The Netherlands). For that purpose, the lyophilized CD11b-antibody conjugated MP-loaded CMCht/PAMAM dendrimer nanoparticles were dispersed in ultrapure water to a final concentration of $1 \mathrm{mg} \cdot \mathrm{mL}^{-1}$, stained with $1 \%$ phosphotungstic acid and placed on copper grids for further observation.

\subsection{In vitro Cell Culture Studies}

\subsubsection{Isolation and Culturing of Rat Cortical Glial Cells}

Neonatal rat cortices were isolated from P4 Wistar rat pups as previously described. ${ }^{[26]}$ Upon removal under aseptic conditions, cortices were maintained in Hanks' balanced salt solution (HBSS, Gibco, USA) and mechanically dissected. Afterwards, the cortical fragments were incubated in an enzymatic medium of $30 \mathrm{mg} \cdot \mathrm{mL}^{-1}$ DNAse solution (Sigma, Germany) with $0.25 \%$ trypsin (Sigma, Germany) in $\mathrm{Ca}^{2+} / \mathrm{Mg}^{2+}$ free HBSS solution for 30 min at $37^{\circ} \mathrm{C}$. The trypsin reaction was blocked adding $40 \%$ foetal bovine serum (FBS, Gibco, USA) and the resulting tissue was centrifuged at $800 \mathrm{rpm}$ for $2 \mathrm{~min}$ and the cells were then plated out at a density of $4 \times 10^{4}$ cells $\cdot \mathrm{cm}^{-2}$ on poly-L-lysine (Sigma, USA) coated coverslips. Glial cells primary cultures were then maintained at $37^{\circ} \mathrm{C}$ in a $5 \%$ $\mathrm{CO}_{2}$ atmosphere, in Dulbecco's modified Eagle medium (DMEM, Gibco, USA) supplemented with 10\% FBS and 1\% antibiotic/ antimycotic for $7 \mathrm{~d}$.

\subsubsection{Establishment of Rat Cortical Microglial Cells}

After the glial cells isolation procedure, these were plated out at a density of $1 \times 10^{6}$ cells $\cdot \mathrm{cm}^{-2}$ in polystyrene T75 flasks (Thermo Scientific, USA) previously coated with poly-L-lysine (Sigma, USA). The glial primary cultures were maintained at $37^{\circ} \mathrm{C}$ in a $5 \% \mathrm{CO}_{2}$ atmosphere in DMEM (Gibco, USA) supplemented with 10\% FBS and $1 \%$ antibiotic/antimycotic for 2 weeks, with periodical medium renewal. After that, the flasks were agitated in an orbital shaker at $240 \mathrm{rpm}$ during $4 \mathrm{~h}$. Following this, the medium containing detached microglia cells was collected and the obtained suspension was centrifuged at $1200 \mathrm{rpm}$ for $5 \mathrm{~min}$. The pellet was re-suspended in DMEM medium (Gibco, USA) supplemented with $10 \%$ FBS and $1 \%$ antibiotic/antimycotic and plated out at a density of $4 \times 10^{4}$ cells $\cdot \mathrm{cm}^{-2}$ on coverslips previously coated with poly-Llysine (Sigma, USA). Microglia cells primary cultures were then maintained at $37^{\circ} \mathrm{C}$ in a $5 \% \mathrm{CO}_{2}$ atmosphere, in DMEM medium (Gibco, USA) supplemented with 10\% FBS and 1\% antibiotic/ antimycotic for $4 \mathrm{~d}$ for further testing.

\subsubsection{In vitro Cytotoxicity Assays}

Unmodified and CD11b antibody-conjugated MP-loaded CMCht/ PAMAM dendrimer nanoparticles were evaluated regarding its influence in the primary cell cultures' viability. For that purpose, two concentrations of nanoparticles were tested: 200 and $400 \mu \mathrm{g} \cdot \mathrm{mL}^{-1}$ and the cultures were exposed to these conditions for a week. For both glial and microglial cell cultures the cell viability was verified after incubation of the cells at $37^{\circ} \mathrm{C}$ for $3 \mathrm{~h}$ with $(3-(4,5-$ dimethylthiazol-2-yl)-5-(3-carboxymethoxyphenyl)-2(4-sulphophenyl)-2H tetrazolium) (MTS, Promega, USA) in a 5:1 ratio. This compound is bioreduced by active dehydrogenase enzymes into a brown formazan product that is released to the medium. After the incubation, the optical density of each sample was read in a multiplate reader (Tecan Sunrise, Switzerland) at $490 \mathrm{~nm}$.

\subsubsection{Internalization Assessment by Immunocytochemistry}

After a week, the glial cultures were incubated with $200 \mu \mathrm{g} \cdot \mathrm{mL}^{-1}$ of CD11b antibody-conjugated and the unmodified FITC-labelled MP-loaded CMCht/PAMAM dendrimer nanoparticles to assess their internalization rates, 1 week after its addition. After this time period, immunocytochemistry was performed. The cells were washed in $0.1 \mathrm{M}$ PBS and fixed in a $4 \%$ paraformaldehyde solution for $30 \mathrm{~min}$. For astrocytes recognition the wells were permeabilized with Triton-X-100 (Merck, Germany) 0.3\% for 5 min, following a new wash in PBS $0.1 \mathrm{M}$. Afterwards, a $10 \%$ FCS solution in PBS was added to the cells for $1 \mathrm{~h}$ and a new wash with PBS $0.1 \mathrm{~m}$ was carried out. The next step consisted on the incubation with the corresponding primary antibody diluted in $10 \%$ FCS in PBS. The following antibodies were used: rabbit anti-rat glial fibrillary protein (GFAP, Dako, Denmark, 1:500) for astrocytes recognition; mouse anti-CD11b (BD Biosciences Pharmingen, USA, 1:100) in microglial cells identification and mouse anti-O4 (R\&D Systems, 1:50) for oligodendrocytes detection. After $1 \mathrm{~h}$ incubation, the cells were washed in $0.5 \%$ FCS in PBS v/v for further $1 \mathrm{~h}$ incubation with the secondary antibodies: Alexa Fluor 594 anti-mouse and Alexa Fluor 568 anti-rabbit (both Molecular Probes, USA, 1:2000) were incubated for $1 \mathrm{~h}$. Negative controls were used performing the same treatment but omitting the primary antibody addition. The cells were then stained with 4',6-diamidine-2-phenyl indole (DAPI, Thermo Scientific, USA, 1:2000), for 5 min in the dark. The coverslips were finally mounted for posterior observation under an Olympus BX-61 Fluorescence Microscope (Olympus, Germany). The FITClabelled dendrimer nanoparticles internalization levels for each cell population were determined according to Equation (1) $(n=3,3$ random fields/coverslip):

$$
I=\frac{P_{\mathrm{c}}}{T_{\mathrm{c}}} \times 100
$$

$I$ is the percentage of internalization, $P_{\mathrm{c}}$ the number of positive cells for FITC-labelled dendrimer nanoparticles and $T_{\mathrm{C}}$ is the total number of each cell type.

\subsubsection{Statistical Analysis}

Statistical evaluation was performed using the one-way analysis of variance test followed by the Tukey's post-test to assess the statistical differences between groups in the viability and internalization tests. Statistical significance was defined for $p<0.05$. 


\section{Results and Discussion}

The partial failure in CNS disorders' pharmacological treatments often resides in the lack of targeting of the administered therapeutic molecules. ${ }^{[4]}$ Even in conditions where the BBB has been compromised and the delivery of compounds is considerably facilitated, as in SCI, efficient drug delivery to target cells should be carefully considered. Due to the massive inflammatory episodes that follow these injuries, a cell-specific drug delivery could be highly advantageous in the control and modulation of these deleterious events. ${ }^{[9]}$ For instance, MP clinical administration as an antiinflammatory drug aggravates a cascade of side effects that could be minimized in a targeted delivery strategy. ${ }^{[27]}$ Following previous works by our group focusing on the development of a CNS targeted dendrimer-based macromolecular carrier, ${ }^{[19,20,23]}$ we aimed at further modify-

ing the CMCht/PAMAM dendrimer nanoparticles to achieve a higher functionalization degree. ${ }^{[28]}$ For this purpose, we tested a new surface modification by conjugating a CD11b antibody to the MP-loaded CMCht/ PAMAM dendrimer nanoparticles. The latter had already shown to be easily internalized by astrocytes, oligodendrocytes and microglial cells present in a mixed primary culture. All these cell types revealed maximum internalization levels $24 \mathrm{~h}$ after exposure to these nanoparticles, being microglial cells the ones with faster uptakes. ${ }^{\left[{ }^{[3]}\right.}$ If we intend to target the delivery of the drug to microglial cells, for instance, minimum amounts should reach the other cell types in order to maximize the desired drug actions while minimizing possible side effects. Therefore, it was investigated whether this generalized internalization intake would be affected by the presence of $\mathrm{CD} 11 \mathrm{~b}$ antibody, which is specific for microglial cell recognition. The CD11b antibody was chosen to facilitate the permeation of the nanoparticles through the microglial cells membrane by specifically interacting with an integrin chain expressed only in this type of cells. In this way, the nanoparticles could still be targeted to microglial cells, but its entrance in the other cell types would be compromised.

In the present study, it was initially investigated the conjugation of the CD11b antibody to the CMCht/PAMAM dendrimer nanoparticles. FTIR spectra of the unmodified and antibody-conjugated CMCht/PAMAM dendrimer nanoparticles are represented in Figure 1A. From Figure 1 , it is visible that the antibody-conjugated nanoparticles disclose an altered FTIR spectrum as com- pared to the unmodified nanoparticles. The $520 \mathrm{~cm}^{-1}$ free amino acid peak and the $1120 \mathrm{~cm}^{-1} \mathrm{NH}_{3}^{+}$vibration appear after modification of the nanoparticles in the antibodyconjugated nanoparticles spectrum. Consequently, the comparative FTIR spectra analysis of the unmodified and $\mathrm{CD} 11 \mathrm{~b}$ conjugated dendrimer nanoparticles seems to suggest that the antibody was, in fact, successfully conjugated to the nanoparticles. Also the ${ }^{1} \mathrm{H}$ NMR spectra of CD11b antibody-conjugated and unmodified CMCht/ PAMAM dendrimer nanoparticles (Figure 1B) revealed new proton signals which indicate that the conjugation actually occurred. Some characteristic peaks of the CMCht/PAMAM dendrimer nanoparticles are maintained in both spectra, such as the $2.17 \mathrm{ppm} \mathrm{CH}_{2}$ protons from the PAMAM dendrimer and the $4.07 \mathrm{ppm} \mathrm{CH}_{2} \mathrm{COO}^{-}$protons from $\mathrm{CMCht}$. Also new signals were observed at $1.26 \mathrm{ppm}$ and $2.71 \mathrm{ppm}$ which are attributed to new $\mathrm{COCH}_{3}$ and $\mathrm{NCH}_{3}$ protons from the newly formed bonds. These new signals strongly suggest that the conjugation of $\mathrm{CD} 11 \mathrm{~b}$ antibody to the nanoparticles actually occurred. Additionally, STEM analysis (Figure 1C) also confirmed the spheric morphology of these nanoparticles.

Regarding the biological assays, both the glial and microglial cell cultures were incubated with two different concentrations of the CD11b-conjugated and the unmodified MP-loaded CMCht/PAMAM dendrimer nanoparticles. The metabolic activity was then quantified by means of performing an MTS assay. In all the tested conditions no negative effect in the normal cell activity was observed (Figure 2). Both cell populations reduced detectable

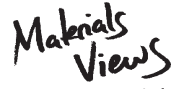

www.MaterialsViews.com 

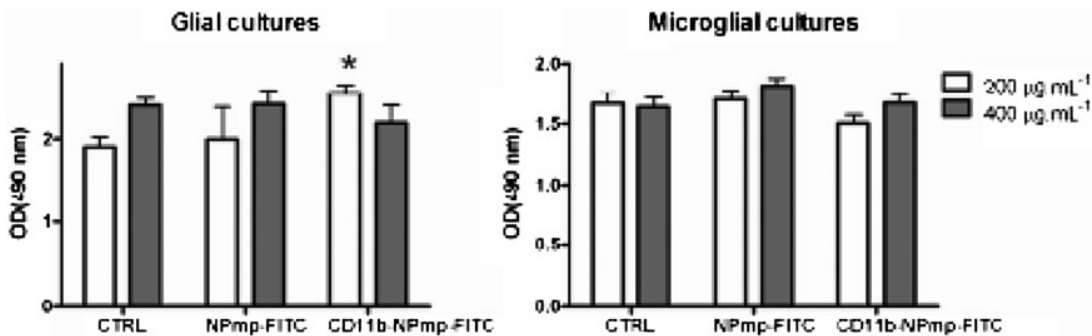

Figure 2. Metabolic activity measured with MTS assay of glial and microglial cultures after exposure to the unmodified (NPmp-FITC) and CD11b conjugated (CD11b-NPmpFITC) CMCht/PAMAM dendrimer nanoparticles. Values are shown as

mean \pm SD $(n=3),{ }^{*} p<0.05$. this mechanism. ${ }^{[30]}$ Thus, our strategy to modify the nanoparticles with an antibody that is efficiently taken up by microglial cells via receptor-mediated endocytosis seems to be advantageous in diminishing the non-specific uptake modulation by other cell types, such as astrocytes and oligodendrocytes. The yield of nanoparticles internalization by microglial cells did not improve, since maximum percentage figures were amounts of MTS in similar ways to those of control cultures, showing normal cell viability and metabolism. Only a slight, but significant, increase in the metabolic activity of glial cells after $200 \mu$ g addition of CD11b-conjugated MPloaded CMCht/PAMAM dendrimer nanoparticles was observed. These data suggest that there is no cytotoxicity derived from the exposure of these cells to the multifunctionalized nanoparticles.

The internalization of the nanoparticles by each cell type in the mixed primary culture of glial cells was then further investigated. To allow both a qualitative and a quantitative evaluation, cells were immunostained for observation and the number of cells containing fluorescently labelled internalized nanoparticles was determined. A previous study has shown that microglial cells presented maximum MP-loaded CMCht/PAMAM dendrimer nanoparticles internalization levels, with all cells evidencing nanoparticles within its cytoplasmic compartment $24 \mathrm{~h}$ after nanoparticles addition. ${ }^{[23]}$ Moreover, astrocytes also reached high internalization levels around $90 \%$ followed by oligodendrocytes, which presented a slightly lower percentage of nanoparticles internalizing cells (around 80\%). As observed in Figure 3 , the $\mathrm{CD} 11 \mathrm{~b}$ conjugation to the MP-loaded CMCht/PAMAM dendrimer nanoparticles did not alter the percentage of microglial cells internalizing the nanoparticles as compared to cultures exposed to MP-loaded CMCht/ PAMAM dendrimer nanoparticles. Importantly, however, this was not true for the other glial cell types. Regarding astrocytes, a drastic and significant decrease in the antibody-conjugated nanoparticles uptake was observed (around 50\%), as seen in Figure 3. Similar to what it was observed in astrocytes, oligodendrocytes also revealed a significant decrease regarding the CD11b-conjugated MPloaded CMCht/PAMAM dendrimer nanoparticles uptake. Again, the number of oligodendrocytes internalizing the modified nanoparticles was drastically reduced to $40 \%$ when compared to the unmodified nanoparticles condition. The endocytosis pathway is believed to be the major route for dendrimer nanoparticles internalization, ${ }^{[21,29]}$ and it was already shown that surface modifications modulate

\section{A)}

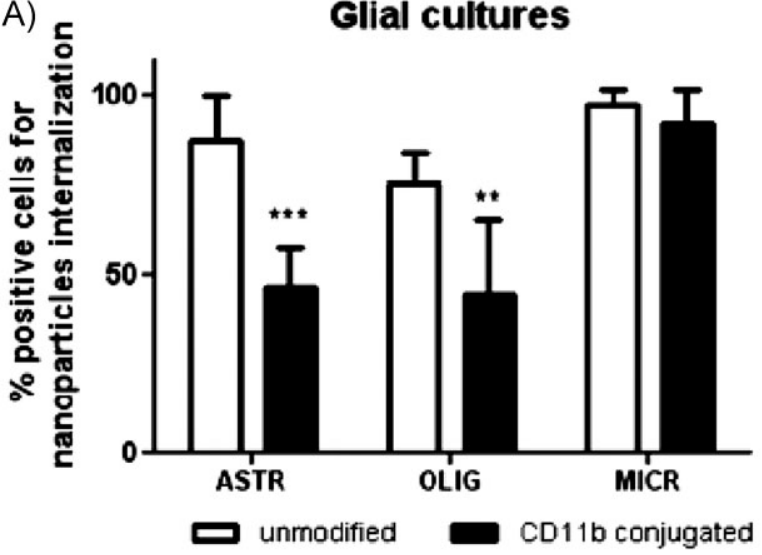

B)

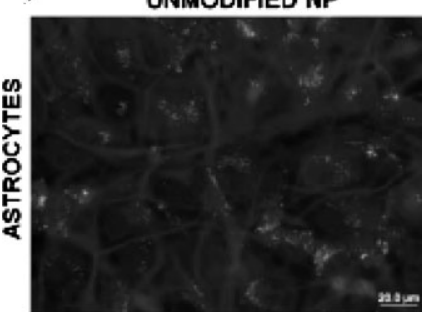

CD11b CONJUGATED NP
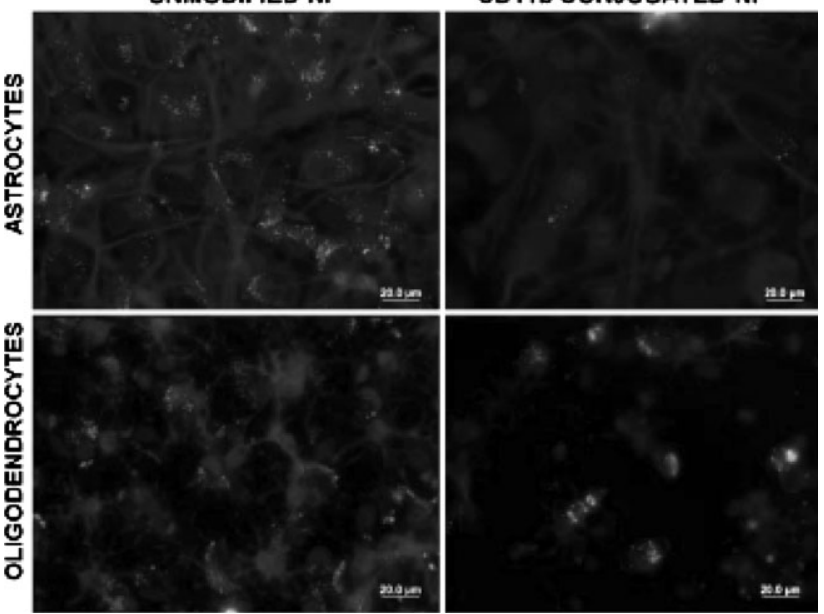

Figure 3. Nanoparticles cell uptake by primary glial cell cultures. (A) The presence of the CD11b antibody in the nanoparticles induced a significant decrease in the number of astrocytes and oligodendrocytes internalizing nanoparticles $7 \mathrm{~d}$ after exposure. $\left(n=3 ; 5\right.$ fields/coverslip; mean \pm SD) ${ }^{* *} p<0.01 ;{ }^{* * *} p<0.001$. (B) Fluorescence microscopy observation of a mixed primary glial culture after immunostaining with anti-GFAP primary antibody for astrocytes labelling and anti-O4 primary antibody for oligodendrocytes recognition. Nuclei were counterstained with DAPI. The cells were exposed to unmodified (left) and CD11b-conjugated MP-loaded CMCht/PAMAM dendrimer nanoparticles (right) during $7 \mathrm{~d}$. 
already being reached. However, the receptor-mediated endocytosis facilitation to microglial cells, due to the interaction of $\mathrm{CD} 11 \mathrm{~b}$ antibody-conjugated nanoparticles, indeed contributed to the improvement of their intracellular uptake and conferred a targeted profile to the system, drastically reducing the uptake by astrocytes and oligodendrocytes.

Thus, we demonstrate that the CD11b antibodyconjugated MP-loaded CMCht/PAMAM dendrimer nanoparticles can be beneficial when envisioning the development of targeted therapies aimed at applications in CNS disorders, namely by carrying anti-inflammatory drugs such as MP to inflammation mediator cells.

\section{Conclusion}

Within the present study it was possible to describe for the first time the successful functionalization of MP-loaded CMCht/PAMAM dendrimer nanoparticles with a microgliaspecific antibody, acting as a targeting ligand. The new sphere-like CD11b antibody-conjugated nanoparticles revealed no cytotoxicity when added to glial and microglial primary cell cultures. Furthermore, a novel nanoparticle uptake profile by astrocytes and oligodendrocytes was achieved with the new modified nanoparticles. These cells significantly reduced the levels of CD11b antibody-conjugated nanoparticles internalization, while maintaining maximum uptake by microglial cells. Further studies will focus on the potential selective anti-inflammatory action of these nanoparticles, namely for SCI applications.

Acknowledgements: The authors would like to acknowledge the Portuguese Foundation for Science and Technology (Pre-Doctoral fellowship to Susana R. Cerqueira SFRH/BD/48406/2008; PostDoctoral fellowship to Joaquim M. Oliveira SFRH/BPD/63175/ 2009; Grant No. PTDC/SAU-BMA/114059/2009; Science 2007 Program - António J. Salgado); the Foundation Calouste de Gulbenkian to funds attributed to António J. Salgado under the scope of the The Gulbenkian Programme to Support Research in the Life Sciences; this work was also partially supported by the European FP7 Project Find and Bind (NMP4-SL-2009-229292).

Received: July 25, 2011; Published online: March 13, 2012; DOI: 10.1002/mabi.201100294

Keywords: CD11b antibody; dendrimers; glial cells; nanoparticles; targeted drug delivery systems

[1] W. M. Pardridge, J. Neurochem. 1998, 70, 1781.
[2] D. Maysinger, A. Morinville, Trends Biotechnol. 1997, 15, 410.

[3] A. V. Kabanov, H. E. Gendelman, Prog. Polym. Sci. 2007, 32, 1054.

[4] D. J. Begley, Pharmacol. Ther. 2004, 104, 29.

[5] G. Modi, V. Pillay, Y. E. Choonara, Ann. NY Acad. Sci. 2010, 1184,154

[6] A. Nowacek, L. M. Kosloski, H. E. Gendelman, NanomedicineUK 2009, 4, 541.

[7] B. V. Zlokovic, Neuron 2008, 57, 178.

[8] W. M. Pardridge, Drug Discovery Today 2007, 12, 54.

[9] D. J. Donnelly, P. G. Popovich, Exp. Neurol. 2008, 209, 378.

[10] M. D. Habgood, N. Bye, K. M. Dziegielewska, C. J. Ek, M. A. Lane, A. Potter, C. Morganti-Kossmann, N. R. Saunders, Eur. J. Neurosci. 2007, 25, 231.

[11] P. G. Popovich, P. J. Horner, B. B. Mullin, B. T. Stokes, Exp. Neurol. 1996, 142, 258.

[12] M. A. Dommergues, F. Plaisant, C. Verney, P. Gressens, Neuroscience 2003, 121, 619.

[13] N. Sanvicens, M. P. Marco, Trends Biotechnol. 2008, 26, 425.

[14] A. Z. Wang, F. Gu, L. Zhang, J. M. Chan, A. Radovic-Moreno, M. R. Shaikh, O. C. Farokhzad, Expert Opin. Biol. Ther. 2008, 8, 1063.

[15] D. Chandrasekar, R. Sistla, F. J. Ahmad, R. K. Khar, P. V. Diwan, Biomaterials 2007, 28, 504.

[16] P. Kocbek, N. Obermajer, M. Cegnar, J. Kos, J. Kristl, J. Controlled Release 2007, 120, 18.

[17] G. A. Hughes, Nanomed. -Nanotechnol. 2005, 1, 22.

[18] L. Zhang, F. X. Gu, J. M. Chan, A. Z. Wang, R. S. Langer, O. C. Farokhzad, Clin. Pharmacol. Ther. 2007, 83, 761.

[19] A. J. Salgado, J. M. Oliveira, R. P. Pirraco, V. H. Pereira, J. S. Fraga, A. P. Marques, N. M. Neves, J. F. Mano, R. L. Reis, N. Sousa, Macromol. Biosci. 2010, 10, 1130.

[20] V. H. Pereira, A. J. Salgado, J. M. Oliveira, S. R. Cerqueira, A. M. Frias, J. S. Fraga, S. Roque, A. M. Falcão, F. M. Marques, N. M. Neves, J. F. Mano, R. L. Reis, N. Sousa, J. Bioact. Compat. Polym. 2011, 26, 619.

[21] J. M. Oliveira, N. Kotobuki, A. P. Marques, R. P. Pirraco, J. Benesch, M. Hirose, S. A. Costa, J. F. Mano, H. Ohgushi, R. L. Reis, Adv. Funct. Mater. 2008, 18, 1840.

[22] J. M. Oliveira, A. J. Salgado, N. Sousa, J. F. Mano, R. L. Reis, Prog. Polym. Sci. 2010, 35, 1163.

[23] S. R. Cerqueira, J. M. Oliveira, J. F. Mano, N. Sousa, A. J. Salgado, R. L. Reis, submitted.

[24] T. A. Waldmann, Science 1991, 252, 1657.

[25] C. Xu, J. Xie, D. Ho, C. Wang, N. Kohler, E. G. Walsh, J. R. Morgan, Y. E. Chin, S. Sun, Angew. Chem., Int. Ed. 2008, 47, 173.

[26] Y. Chen, V. Balasubramaniyan, J. Peng, E. C. Hurlock, M. Tallquist, J. Li, O. R. Lu, Nat. Protoc. 2007, 2, 1044.

[27] D. C. Baptiste, M. G. Fehlings, Prog. Brain Res. 2007, 161, 217.

[28] N. T. K. Thanh, L. A. W. Green, Nano Today 2010, 5, 213.

[29] L. Albertazzi, M. Serresi, A. Albanese, F. Beltram, Mol. Pharm. 2010, 7, 660.

[30] A. Saovapakhiran, A. D’Emanuele, D. Attwood, J. Penny, Bioconjugate Chem. 2009, 20, 693.

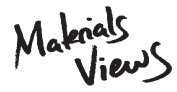

www.MaterialsViews.com
Macromol. Biosci. 2012, 12, 591-597

(C) 2012 WILEY-VCH Verlag GmbH \& Co. KGaA, Weinheim 